\title{
Discutindo estratégias para o ensino de literatura no contexto de educação de jovens e adultos surdos
}

Discussing strategies for the teaching of literature in the context of deaf education

Alessandra Gomes da Silva, mestranda em Literatura, Cultura e Contemporaneidade (PUC-Rio), Instituto Nacional de Educação de Surdos (INES), aletrasufrj@yahoo.com.br;

Selma de Oliveira Ramos, Especialista em Educação, Instituto Nacional de Educação de Surdos (INES), sejadines@yahoo.com.br.

\section{Resumo}

O presente trabalho tem como objetivos descrever e analisar estratégias utilizadas para o ensino de literatura, no contexto de educação bilíngue, com alunos da educação de jovens e adultos surdos. Para isso, tem-se como base aulas de literatura e oficina de leitura, ministradas no colégio de aplicação do INES (capINES).

Palavras Chave: Surdos, Literatura, LIBRAS.

\section{Abstract}

This paper aims to describe and analyze strategies used for the teaching of literature in the context of bilingual education with students in an education program for deaf young people and deaf adults. The discussion is based on literature classes and a reading workshop taught in the school for deaf people (INES).

Keywords: Deaf, Literature, Brazilian Sign Language. 
"A literatura desconcerta, incomoda, desorienta, desnorteia mais que os discursos filosófico, sociológico ou psicológico porque ela faz apelo às emoções e à empatia. Assim, ela percorre regiões da experiência que os outros discursos negligenciam, mas que a ficção reconhece em seus detalhes." (COMPAGNON, Antoine, Literatura para quê? Tradução de Laura Taddei Brandini, p.54)

Durante toda a história da civilização, modos e práticas de narrar são utilizados para comunicar a experiência. Grupos e sujeitos lutam para alterar a forma de participação nas histórias e legitimar discursos sobre si e sobre os outros. Pela palavra a vida de uma pessoa pode ser contada. Descobrimos formas de ser e de pensar por ela também. Desse modo, ressaltamos a importância do narrar, pois, segundo Fernandes (2009:50), "não podemos compreender nossa cultura sem compreender as histórias que estão sendo contadas e como". Mais adiante, complementa que "é em meio a esse contar e recontar de histórias que todos fomos formados". Isso porque pelas narrativas podem ser passados costumes, ritos e tradições. Assim se constroem saberes, valores e sentimentos que marcam a identidade e a noção de pertencimento ao grupo. Nesse emaranhado de histórias, escolhemos, então, como objeto de nossa reflexão a recepção dos textos literários, tendo como base o contato com algumas narrativas ficcionais por alunos surdos adultos.

Nesse sentido, o presente trabalho tem como objetivos descrever e analisar estratégias utilizadas para esse ensino de literatura, no contexto de educação bilíngue, com alunos da educação de jovens e adultos surdos. Para isso, tem-se como base aulas de literatura e oficina de leitura, ministradas no colégio de aplicação do Instituto Nacional de Educação de Surdos (cap-INES). Assim, em nossa seleção de textos para o trabalho de literatura nos interessam tanto os temas abordados, seja por sua possibilidade de alcance social, seja pelas discussões que podem suscitar como o modo como foi construído o texto, ou seja, o trabalho com a linguagem.

Nesse contexto, faz-se necessário compreender que com a publicação da lei de LIBRAS, (Língua Brasileira de Sinais, 2002)', agora com o status de língua, reconhece-se, por conseguinte, o direito de o surdo ter acesso a uma língua que seria sua língua natural, como $1^{\circ}$ língua, ponto de partida para qualquer outra aprendizagem. Desse modo, tais alunos vivenciam uma experiência de bilinguismo compulsório, uma vez que são usuários da língua de sinais e devem aprender a língua portuguesa, em sua modalidade escrita, como segunda língua. 
Nesse sentido, no presente trabalho, enfocamos os processos envolvidos na construção da habilidade de leitura, sobretudo a literária, e a possibilidade de relacioná-la ao conhecimento de mundo e ao próprio contexto desses alunos. Para isso, partimos sempre de uma concepção de leitura na perspectiva dos estudos do letramento, segundo o qual, citando Kleiman (1995:8), visa ao "ensino de escrita/leitura das tecnologias das sociedades letradas como uma das formas de se potencializar o cidadão para lidar com as estruturas de poder na sociedade". Acreditamos, por conseguinte, que o desenvolvimento dessa habilidade deva favorecer tanto uma leitura crítica dos textos, como da própria sociedade, podendo implicar em significativas diferenças nos modos desses sujeitos de ser e de estar no mundo.

Dessa forma, sabemos que a escola, no entanto, sempre prezou por manter algum tipo de homogeneidade, seja em sua organização, na disposição dos moveis nas salas, nas idades dos alunos, numa tentativa, por vezes falha, de equivalência nos ritmos e nos processos de aprendizagem. Além disso, há tentativa de separação nítida entre os momentos de estudo e de lazer.

Isso acontece porque ainda pensamos em nosso trabalho, tendo como base grupos uniformes de alunos, com práticas culturais similares. Sabemos, entretanto, que, na realidade, há uma necessidade constante de negociação entre as experiências que os alunos trazem consigo e o saber escolar institucionalizado, principalmente na figura do professor, para que haja efetiva produção de conhecimento. Assim, por apresentarmos uma experiência de trabalho com a diversidade, tanto pelo trabalho com alunos surdos, como pelo público de Jovens e Adultos, acabamos por nos deter em questões que abordam o multiculturalismo e as diferenças na escola. Ainda por trabalharmos com os gêneros literários, acreditamos que esse possa ser um viés lúdico e, ao mesmo tempo, eficiente para a discussão de códigos e estruturas sociais que norteiam nossas vidas. Nesse sentido, por meio da arte, podemos entrar em contato com outras culturas, sensibilizandonos às diferenças e nos fazendo repensar nossa própria forma de viver. Tais questões são importantes principalmente por compreendermos que a escola vem abarcando grupos dos mais diversos. Isso decorre, sobretudo, de uma tentativa de democratização do acesso e buscando estratégias para a permanência de segmentos sociais historicamente marginalizados, dando-lhes condições à escolarização formal. Tais grupos, no entanto, acabam por se sentirem, muitas das vezes, excluídos do sistema, já que não se veem valorizados nos seus usos de linguagem e em suas práticas culturais que a escola, como dissemos anteriormente, não reconhece, nem legitima.

Deve-se considerar também a importância do ensino desse segmento incluir textos narrativos, pois, segundo Leahy-Dios (2000:18), "ao mesmo tempo em que lida com o sensorial, o emocional e o racional de indivíduos e de grupos sociais, a literatura atua na comunicação de ideias, sentimentos, emoções e pensamentos". 
Nesse sentido, a autora, mais adiante, esclarece que além da análise de língua ou da arte, por meio da literatura há a possibilidade de "análise de determinadas representações culturais da sociedade", (2000:48). Com isso, propõe-se que a escola seja um lugar de experimentação de diferentes possibilidades de leitura e, a partir desse contato com os textos, possa se promover um espaço maior para o questionamento de alguns posicionamentos sociais, tais como, por exemplo, questões de gênero e raça, questões relativas à surdez e aos surdos. Do mesmo modo, não se pode desconsiderar que grande parte das histórias que compõem nosso imaginário sociocultural é quase que totalmente desconhecida dos alunos surdos dos cursos noturnos.

Além disso, a opção por abordar tais relações multiculturais em sala de aula, como destaca Maher (2007:300), nos permite pensar em concepções de ensino que visam rejeitar a 'essencialização' dos sujeitos. Isso porque tais concepções acabam por acreditar que o comportamento de todo e qualquer membro de um segmento minoritário, por exemplo, dos surdos, seria a única experiência autêntica capaz de representar tal grupo, ignorando os conflitos e contradições existentes no interior da própria comunidade. Dessa forma, são produzidos estereótipos que mantêm e reforçam as diferenças. Nesse sentido, para Skliar (1997:33), tais sujeitos "não são reconhecidos nos diferentes e múltiplos recortes de sua identidade, linguagem, raça, gênero, idade, comunidade, culturas, etc", sendo reduzidos, assim, ao fato de não 'ouvirem'.

Nesse contexto, citando Naiditch, o uso da literatura em sala de aula, infelizmente, tem sido defendido, basicamente, como uma forma de 'introduzir' aspectos gramaticais na escola. A literatura, no entanto, se configura num espaço privilegiado para a discussão de códigos e valores sociais que estruturam nossas vidas, trazendo as vozes dos mais variados grupos, possibilitando à 'inserção' de setores minoritários, quase sempre, marginalizados, ou excluídos, de nossa sociedade. Por conseguinte, a literatura torna-se um veiculo para a comunicação de ideias, sentimentos e emoções, sobretudo quando pensamos em uma educação bilíngue, pois, nesse contexto, já estamos pensando, consequentemente, em uma formação intercultural e híbrida.

Nota-se ainda que, atualmente, o conceito de leitura envolve o domínio de diversas linguagens que caracterizam nossa sociedade multissemiótica (Rojo, 2009). Desse modo, com a possibilidade do uso de tecnologias em nossas salas de aula, esperamos que se multipliquem também a diversidade de narrativas. Busca-se, então, contribuir na formação de leitores mais eficientes e criativos, que sejam capazes de relacionarem informações que envolvam diferentes linguagens, entre imagens e textos. Sabe-se que muitas dessas linguagens não se limitam apenas ao uso da imagem ou ao uso da palavra, mas funcionam na imbricação de tais códigos, que terminam por implicar em formas diferenciadas de apropriação da mensagem. 
Tais possibilidades de uso das tecnologias no contato com os textos literários tornam-se importante uma vez que encontramos alunos adultos que chegam ao Instituto com conhecimento de língua de sinais bastante variável. Em alguns casos, há alunos que pouco ou nada conhecem de LIBRAS e, em sua maioria, alunos que ainda estão em fase inicial da aprendizagem de sua própria língua, em situação formal de ensino (Loureiro, 2001). Desse modo, percebe-se que os alunos desse segmento ainda se deparam com barreiras linguísticas que dificultam o seu acesso à informação e continuam bastante cerceados em sua possibilidade de compreensão do mundo.

A metodologia utilizada para este trabalho corresponde a da pesquisa-ação. Nesse sentido, para a geração dos dados aqui analisados foi proposto um conjunto de 'rodas de leitura'. Nesse contexto, nossas atividades envolveram, inicialmente, a leitura coletiva de diferentes gêneros literários. Um dos textos escolhidos para o trabalho com as turmas de primeiro segmento do Ensino Fundamental foi o conto "Para que ninguém a quisesse", de Marina Colasanti. A leitura foi realizada com turmas do $4^{\circ}$ e $5^{\circ}$ anos do turno noturno. Foram retiradas dúvidas de vocabulário e o texto foi amplamente debatido em sala, discutindo questões como as relações amorosas e respeito ao próximo, além da própria violência doméstica, com um uso excessivo de poder e dominação. Os alunos participaram efetivamente da leitura, expressando suas interpretações para o que foi lido e esboçando opiniões sobre a narrativa. Como lidamos com alunos adultos, a seleção de temas e textos torna-se importante para que não corramos o risco de infantilizar tais sujeitos e negligenciarmos os saberes e vivências que eles trazem consigo.

Em um segundo momento, foi proposta uma transposição do texto para a produção de um vídeo. Tais vídeos demonstram possibilidades de narrar em outra linguagem, promovendo releituras de textos de grande circulação. Nesse sentido, a contação de história proposta pela turma na produção do pequeno filme começou com uma disposição lenta e gradual dos elementos recolhidos por uma das alunas para representar os elementos narrados no texto que provocam o ciúme do companheiro. Tem-se assim o batom, perfume, maquiagem e o vestido, todos escolhidos para compor a cena pensada por ela. Nesse sentido, são nos pequenos arremates, nas pequenas incursões que os alunos promovem que marcam suas formas de interpretar. Outras linguagens vão sendo incorporadas às narrativas, modificando o modo de narrar, mas que, ao mesmo tempo, atualizam práticas anteriores, ressignificando-as.

Já a segunda cena que também gostaríamos de comentar corresponde a um momento em que um grupo de rapazes deve mexer com a moça e provocar a ira do companheiro ciumento. Tem-se em cena alunos de diferentes séries da noite que devem articular como deve ser sua ação para que a imagem retrate sem a presença de um narrador a história do conto. Nesse contexto, um dos alunos mais velhos toma a iniciativa e explica aos demais como devem proceder. Explica-lhes que 
devem seguir seu movimento, inicialmente, fingindo que conversam despreocupados, e quando a moça passar por eles, todos deveriam parar a conversa e voltar-se para o casal de jovens. Posteriormente, continua o aluno assumindo a criação da cena, ao seu sinal, os demais colegas deveriam voltar aos seus lugares e a câmera se moveria para a discussão do casal e a reação explosiva do namorado. Desse modo, os próprios alunos discutem e produzem suas próprias leituras para a narrativa. Sabe-se que um texto literário, sobretudo, em uma segunda língua apresenta um esforço significativo de leitura que pode afastar ou, pelo menos, desestimular os novos leitores que ainda se encontram num processo inicial de letramento. O que pode se ver na atividade exemplificada, como em outras realizadas, sobretudo as que também envolveram transposição de linguagem, foi um despertar do interesse desses alunos para a leitura das narrativas, com um visível envolvimento nas atividades.

Com esta proposta, portanto, visamos colaborar para a discussão da possibilidade de uso de narrativas literárias, em seus múltiplos gêneros e suportes, contribuírem na construção de uma pedagogia mais atenta as necessidades e interesses de nossos alunos, tornando-os mais conscientes de seus posicionamentos e escolhas, possibilitando, por fim, uma ampliação crítica de seu repertório cultural. Houve ainda diversos trabalhos realizados com as turmas, dentre os quais, a leitura de uma adaptação do texto 'A ratinha branca de Pé-de-vento', de Jorge Amado, em comemoração ao centenário do autor. Junto com o texto foram lidas algumas letras de música que abordavam o tema da Bahia para ajudar a compor o cenário tão utilizado pelo autor. Tais textos foram discutidos em sala com uma ampla exposição de vídeos e imagens que podem ajudar na compreensão dos alunos, uma vez que a adaptação de Jorge Amado corresponde a um texto mais longo e que exige um maior empenho por parte dos nossos alunos leitores.

Podemos destacar outro trabalho desenvolvido com as turmas como, por exemplo, a turma de 40 ano, em que foi desenvolvida uma história em quadrinhos (fotonarrativa), a partir da leitura de charges, principalmente, sobre o tema da corrupção. Nesse sentido, foram selecionadas algumas charges que abordassem o tema e, posteriormente, tais textos foram analisados por nossos alunos que discutiram amplamente as questões. Depois, foi organizado um roteiro prévio, selecionado, pelos próprios alunos, os personagens e fotografamos as cenas da narrativa pensada. Foi importante mostrar nas tirinhas e mesmo nas charges a importância das expressões dos personagens - tristeza, alegria, susto, além da própria linguagem corporal que são elementos que garantem a compreensão do texto nesses gêneros, ao mesmo tempo em que foi pontuada a organização da narrativa nos quadrinhos, que é estruturada em cenas dispostas consecutivamente. Em seguida, foram colocados os balões e as onomatopeias, com a turma se revezando para a escrita do texto. Por fim, os alunos escolheram o título. Ressaltamos que durante o período da produção textual, as dúvidas de vocabulário 
e de construção das sentenças eram sanadas e cada grupo lia o texto já finalizado anteriormente no inicio de cada aula. Ao final da atividade, toda a história foi organizada no formato de quadrinhos e impressa para que os alunos vissem a produção final de seu trabalho que ficou exposto na escola.

Assim, espera-se com isso ainda encontrar pistas que possam ajudar os educadores em geral e, sobretudo, de surdos nos processos de letramentos desse grupo. Espera-se, assim, justificar nosso interesse em discutir tais questões, uma vez que, reiteramos, a literatura pode contribuir efetivamente para a construção de saberes e subjetividades importantes para esse segmento. Reforça-se a complexidade da situação pelo fato de que não dispomos de muitos materiais para o trabalho com tais alunos. Materiais nos quais se considerem suas especificidades linguísticas, os seus interesses e suas necessidades.

Nota

i. LIBRAS é a abreviação utilizada pelos surdos brasileiros para designar a Língua de Sinais do Brasil. A LIBRAS foi oficializada pelo decreto-lei 10.436 de 24/04/2002 cujo texto foi regulamentado pelo decreto no 5.626, publicado em 23/12/2005, no Diário Oficial da União, nº 246 (pág. 28, 29 e 30).

\section{Referências Bibliográficas}

FERNANDES, Adriana Hoffmann. Infância e cultura: o que narram as crianças na contemporaneidade? Brasil, 2009. 241 f. Tese (Doutorado em Educação), Programa de Pós-graduação em Educação, Universidade do Estado do Rio de Janeiro, Rio de Janeiro, 2009.

NAIDITCH, F. Literatura Multicultural e diversidade na sala de aula. Educação, Porto Alegre, v. 32, n.1, jan./abr, 2009. (p. 25-32)

KLEIMAN, A. (Org.). Modelos de Letramento e as práticas de Alfabetização na escola. In: Os significados do letramento. Campinas: Mercado de Letras, 1995.

LEAHY-DIOS, C. Educação Literária como metáfora social: desvios e rumos. Niterói: Ed. UFF, 2000.

LOUREIRO, V. R. Aquisição de Língua Brasileira de Sinais por surdos adultos: uma proposta de trabalho. Revista Espaço, Rio de Janeiro: INES, $n^{\circ} 15$, 2001. (p.61-66).

ROJO, R. Letramentos múltiplos, escola e inclusão social. São Paulo: Parábola, 2009. 
SKLIAR, C. A educação para os surdos entre a pedagogia especial e as políticas para as diferenças. In: Anais do Seminário Desafios e possibilidades na Educação bilíngüe para surdos, INES, 1997.

MAHER, Tereza. A educação do entorno para a interculturalidade e o plurilingüísmo. In: KLEIMAN, A.; CAVALANTI, M.C. (orgs.). Lingüística aplicada - suas faces e interfaces. Campinas: Mercado de Letras, 2007. 